\title{
Response of equatorial ionosphere to episodes of asymmetric ring current activity
}

\author{
J. H. Sastri", M. A. Abdu, J. H. A. Sobral \\ Instituto Nacional de Pesquisas Espaciais (INPE), CP 515, 12201-970 São José dos Campos-SP, Brazil
}

Received: 12 November 1996 / Revised: 19 March 1997 / Accepted: 1 April 1997

\begin{abstract}
We present the characteristics of the response of equatorial ionospheric zonal electric field and Fregion plasma density to the asymmetric ring current intensifications that occurred in succession on 16 December 1991, corresponding to the STEP/EITS-2 campaign period. The study is based on high-timeresolution (1-min) data of asymmetic ring current indices, ASY(H/D) and F-region vertical plasma drift, $V_{z}$ measurements at Kodaikanal $\left(10.25^{\circ} \mathrm{N} ; 77.5^{\circ} \mathrm{E}\right.$; dip $4^{\circ}$ ), India and quarter-hourly ionosonde data of Fortaleza $\left(4^{\circ} \mathrm{S}\right.$; $322^{\circ} \mathrm{E}$; dip $\left.-9^{\circ}\right)$, Brazil. It is shown that short-lived disturbances in F-layer vertical plasma drift, $V_{z}$ and height $\left(\mathrm{h}^{\prime} \mathrm{F} / \mathrm{hpF} 2\right)$ indicative of westward and eastward electric fields prevail simultaneously in the dusk (18-21 LT) and predawn (02-05 LT) sectors, respectively, in association with the decay phase of asymmetic ring current events. Electric fields of opposite polarity do also seem to manifest at these local times, particularly in the early-morning sector in conjunction with the intensification of the asymmetric ring current. At a given location, electric field disturbances associated with individual asymmetric ring current events are thus bipolar in nature, with fields of opposite polarity during the growth and decay phases. The nature and polarity structure of the observed electric field disturbances are in agreement with the theoretical/model predictions of prompt penetration of high-latitude electric fields to the equatorial region.
\end{abstract}

\section{Introduction}

A fairly large body of literature now exists to show that at the time of geomagnetic substorms/storms the ionospheric electric fields/currents and plasma density

\footnotetext{
* On sabbatical leave from Indian Institute of Astrophysics, Bangalore, India
}

in the dip equatorial region depart quite significantly on different time-scales from the geomagnetically quiet time patterns (see Abdu et al., 1991, 1993, 1995; Fejer, 1991; Fejer and Scherliess, 1995; Reddy et al., 1990; Reddy and Nishida, 1992; Sastri et al., 1992a,b,c, and references therein). Geomagnetic activity is found to influence preferentially the zonal rather than the meridional component of the ionospheric electric field at dip equatorial locations (e.g. Gonzales et al., 1983; Fejer et al., 1985). The geomagnetic activity-related disturbances in the equatorial zonal electric field/currents are broadly classified into two groups depending on their nature and duration (rapid changes of short duration or slowly varying and persistent changes), and on the timedelay of their appearance with reference to the causative geomagnetic disturbance (prompt or delayed effects). We are primarily concerned here with the group of short-lived $(\approx 2$-h duration) electric field perturbations which most often occur in close temporal association with auroral substorm and symmetric/asymmetric ring current activities. These electric field disturbances are currently understood as manifestations of direct penetration to low latitudes of electric fields of magnetospheric/high-latitude origin (e.g. Fejer et al., 1990a,b; Sastri et al., 1992a,b,c; Abdu et al., 1993, 1995; Fejer and Scherliess, 1995), based on the results of numerical and semi-analytical model studies of electric field perturbations in the plasmasphere due to sudden changes in the magnetospheric convection (polar-cap potential drop) and in field-aligned current (FAC) systems (e.g. Nopper and Carovillano, 1978; Senior and Blanc, 1984; Tsunomura and Araki, 1984; Spiro et al., 1988). Persistent (several-hours duration) and slowly varying electric field disturbances which follow the onset of magnetic storms/substorms with long delays $(>6 \mathrm{~h})$ and with a polarity opposite to the quiet-time electric field pattern at practically all local times constitute the other group (Fejer et al., 1983; Sastri, 1988; Mazaudier and Venkateswaran, 1990, Fejer and Scherliess, 1995). These are interpreted in terms of the disturbance dynamo mechanism, wherein modifications 
in global thermospheric circulation brought about by stormtime energy input to the high-latitude thermosphere-ionosphere system lead to generation of electric fields at low latitudes (Blanc and Richmond, 1980).

Against this background, the present work is done with the primary aim of evaluating the longitude/localtime dependence of the response of equatorial zonal electric field to asymmetric ring current intensifications, using simultaneous ionospheric data of Indian $\left(75^{\circ} \mathrm{E}\right)$ and Brazilian $\left(45^{\circ} \mathrm{W}\right)$ sectors. While the earlier studies have documented the global nature and polarity pattern of electric field disturbances associated with asymmetric (partial) ring current events (Tanaka, 1981, 1986; Gonzales et al., 1979; 1983), recent studies have drawn particular attention to the high sensitivity of the electric field in the dusk and postmidnight sectors to asymmetric ring current developments, using essentially single-station data (Sastri et al., 1992c; Abdu et al., 1993, 1995) The current work substantiates this prominent feature of the local-time dependence of the electric field disturbances associated with asymmetric ring current events. Moreover, though the polarity of the electric field disturbances associated with asymmetric ring current substorm activity is known from earlier studies to be opposite in the day and night hemispheres (Gonzales et al., 1979, 1983; Sastri et al., 1992b), evidence for the simultaneous response, with opposite polarity, of electric fields in the predawn and dusk sectors, to asymmetric ring current activity is reported for the first time here. The present results, therefore, constitute an addition to the growing experimental knowledge of the characteristics of short-lived equatorial electric field disturbances associated with asymmetric ring current activity.

\section{Database}

We have analysed the simultaneous high-time resolution (1-min) measurements of F-layer vertical plasma drift, $V_{z}$ made at Kodaikanal $\left(10.25^{\circ} \mathrm{N} ; 77.5^{\circ} \mathrm{E}\right.$; dip $\left.4^{\circ}\right)$, India, with a HF pulsed Doppler radar and 15-min ionosonde data of Fortaleza $\left(4^{\circ} \mathrm{S} ; 322^{\circ} \mathrm{E}\right.$; dip $\left.-9^{\circ}\right)$, Brazil, for the perturbations in equatorial zonal electric field and $\mathrm{F}$ region plasma density associated with asymmetric ring current activity. Also used are the low-time-resolution (1-h) ionosonde data of Kodaikanal and ionospheric electron content (IEC) measurements at São José dos Campos $\left(22.6^{\circ} \mathrm{S} ; 315^{\circ} \mathrm{E}\right.$; dip -28 $)$, Brazil, using the $136-$ $\mathrm{MHz}$ beacon transmissions from GOES-1 satellite.

The HF pulsed phase path (Doppler) radar at Kodaikanal provides continuous information on the time rate of change of phase path (Doppler frequency shift) of reflections from discrete ionospheric regions at normal incidence with a time resolution of $6 \mathrm{~s}$ and a group height resolution of $1.5 \mathrm{~km}$ (Sastri et al., 1985). The radar is regularly operated on a probing frequency of $4 \mathrm{MHz}$ during the evening-night-time hours (17000600 LT) to study the dynamics of the nocturnal equatorial $\mathrm{F}$ region. The time rate of change of phase path, del $\mathbf{P} /$ del $\mathbf{t}$ of F-layer reflections at vertical incidence during evening/night-time hours is primarily a measure of vertical plasma motion near the reflection point because of the negligible contribution of electron density changes below the reflection level at such local times. $V_{\mathrm{z}}$ is then $0.5 \mathrm{del} \mathbf{P} /$ del $\mathbf{t}$ which, at and near the dip equator, represents the combined effects of electromagnetic $\boldsymbol{E} \times \boldsymbol{B}$ drift and an apparent upward drift due to chemical loss. The later is estimated to be negligible in the evening-night-time hours provided the height of reflection is $>300 \mathrm{~km}$ (Bittencourt and Abdu, 1981). This condition is usually met in the postsunset hours but not in the later part of the night. Corrections for layer decay due to chemical loss (vertical drift due to chemical loss, $V_{\beta}=\beta H$, where $\beta$ is the loss coeffecient and $H$ is the electron density scale height) are then made following standard procedure (see for example, Sastri et al., 1992a).

The use of F-layer height parameters, $h p F 2 / h^{\prime} F$ is an indirect but widely adopted method for deriving information about F-layer vertical plasma drift and hence about the zonal electric field responsible for it (e.g. Abdu et al., 1981; Batista et al., 1991; Sastri et al., 1992a,b,c; Abdu et al., 1995). During evening and night-time, the time rate of change of $h^{\prime} \mathrm{F}$ (the minimum virtual height of bottomside $\mathrm{F}$ region) yields reliable information on vertical plasma drift so long as $\mathrm{h}^{\prime} \mathrm{F}$ is $>300 \mathrm{~km}$. During daytime, hmF2 (the height of peak electron density) or hpF2 (a parabolic approximation of the same that is directly read from the ionograms) could serve the same purpose depending on the temporal evolution of the electric field. It is to be noted that hpF2 could differ from $\mathrm{hmF} 2$ by upto $50 \mathrm{~km}(10 \mathrm{~km})$ during daytime (night-time), but the temporal variations in the two will be nearly the same.

We have used 1-min-resolution data of F-layer $V_{\mathrm{z}}$, at Kodaikanal primarily to match the resolution of the asymmetric ring current indices, ASY $(H / D)$. The ASY indices represent the asymmetric ring current activity as seen in mid-latitude magnetograms (see Iyemori and Rao, 1996, and references therein for details of the derivation of the indices), which is known to correlate well with the southward component of IMF $B_{\mathrm{z}}$ as well as with the auroral electrojet indices (Clauer and McPherron, 1980; Clauer et al., 1983). They thus serve as a gross indicator of substorm activity. Analysis of geomagnetic and ionospheric data of high time resolution, as is done to some degree here, is very desirable to assess the polarity structure of the short-lived electric field disturbances and its relationship to the phase(s) of the asymmetric ring current event. This is in line with the current view that specific consideration of the phase of substorm activity is necessary to advance our understanding of the physical processes operative at the different phases (e.g. Kamide et al., 1996).

\section{Observations}

The present work focuses on the asymmetric ring current events that occurred in quick succession on 16 
December 1991 corresponding to the second campaign of EITS Project within WG 3 of the International SolarTerrestrial Energy Program (STEP).

Figure 1 shows the time histories of the $\operatorname{ASY}(H)$ and ASY (D) indices for 16 December 1991, a moderately disturbed day $(\mathrm{Ap}=20 ; \mathrm{F} 10.7=225.1)$. The temporal profile of the symmetric ring current index, $\operatorname{SYM}(H)$, which is essentially the same as the hourly equatorial Dst index but for the time resolution, is also shown to indicate the state of the magnetospheric ring current. It is apparent from Fig. 1 that the asymmetric ring current underwent three successive and distinct intensifications (peak amplitude of ASY $<90 \mathrm{nT}$ ) over the period 1200 UT on 16 December. These events were preceded by very quiet geomagnetic conditions for $12 \mathrm{~h}$, and the previous day, 15 December, was also geomagnetically quiet $(\mathrm{Ap}=7, \mathrm{Kp}<3)$. The fortuitous occurrence of three successive asymmetric ring current events over a 12-h interval on 16 December provided a unique opportunity to evaluate the local-time dependence of the electric field disturbances associated with them, from the simultaneous ionospheric data of dip equatorial stations in India and Brazil.

Figure 2 shows the variations in the $\operatorname{ASY}(H)$ index, F-layer $V_{z}$ at Kodaikanal and $\mathrm{h}^{\prime} \mathrm{F} / \mathrm{hpF} 2$ at Fortaleza over the time-interval 1130-0000 UT on 16 December 1991. The average values of the same parameters at the two stations corresponding to six quiet days of the month (with $A p<10$ ) are also shown in the figure (solid circles) to serve as a reference. It is to be clarified here that the average quiet-day pattern of $V_{z}$ at Kodaikanal shown in Fig. 2 corresponds to the one obtained by smoothing the 1-min values with a running mean filter of 55 -min width. This is done to suppress the short-period $(<1-\mathrm{h})$ fluctuations in $V_{z}$ which are a common feature of the temporal structure of $V_{z}$ at dip equatorial stations (e.g. Earle and Kelley, 1987; Nair et al., 1992) and to show essentially the ambient vertical plasma drift pattern. The average quiet-day patterns of $V_{z}$ at Kodaikanal and $\mathrm{h}^{\prime} \mathrm{F}$ at Fortaleza shown in Fig. 2 clearly show the well-known postsunset enhancement of F-layer vertical drift/height in the vicinity of the dip equator, which is widely considered as being due to F-region dynamo electric fields (see for example, Farley et al., 1986; Batista et al., 1986; Crain et al., 1993, and relevant references therein).

The behaviour of $V_{z}$ at Kodaikanal and $\mathrm{h}^{\prime} \mathrm{F} / \mathrm{hpF} 2$ at Fortaleza on 16 December 1991 departed quite significantly from the quiet-day pattern in consonance with the episodes of asymmetric ring current activity spanning about half a day, as can be seen from Fig. 2. At Kodaikanal, the upward vertical drift underwent an impulsive increase from about $20 \mathrm{~m} / \mathrm{s}$ to about $33 \mathrm{~m} / \mathrm{s}$ over the time-interval 1230-1255 UT (1730-1755 LT), followed by a conspicious reduction to $5 \mathrm{~m} / \mathrm{s}$ by 1315 UT (1815 LT) and to an eventual downward drift of about $10 \mathrm{~m} / \mathrm{s}$ by 1400 UT (1900 LT). The initial increase and subsequent decrease and reversal in upward drift occurred in close temporal association with the development and decay phases of the asymmetric ring current, respectively. It is noteworthy that the anomalous downward drift, as well as the decay of the asymmetric current, occurred in a stepwise manner. The net change in drift from 30 to $-10 \mathrm{~m} / \mathrm{s}$ during the recovery phase corresponds to a westward electric field of about $1.6 \mathrm{mV} / \mathrm{m}$. This plasma drift disturbance indicates the prevelance of a bipolar electric field perturbation at Kodaikanal in the dusk sector, i.e.

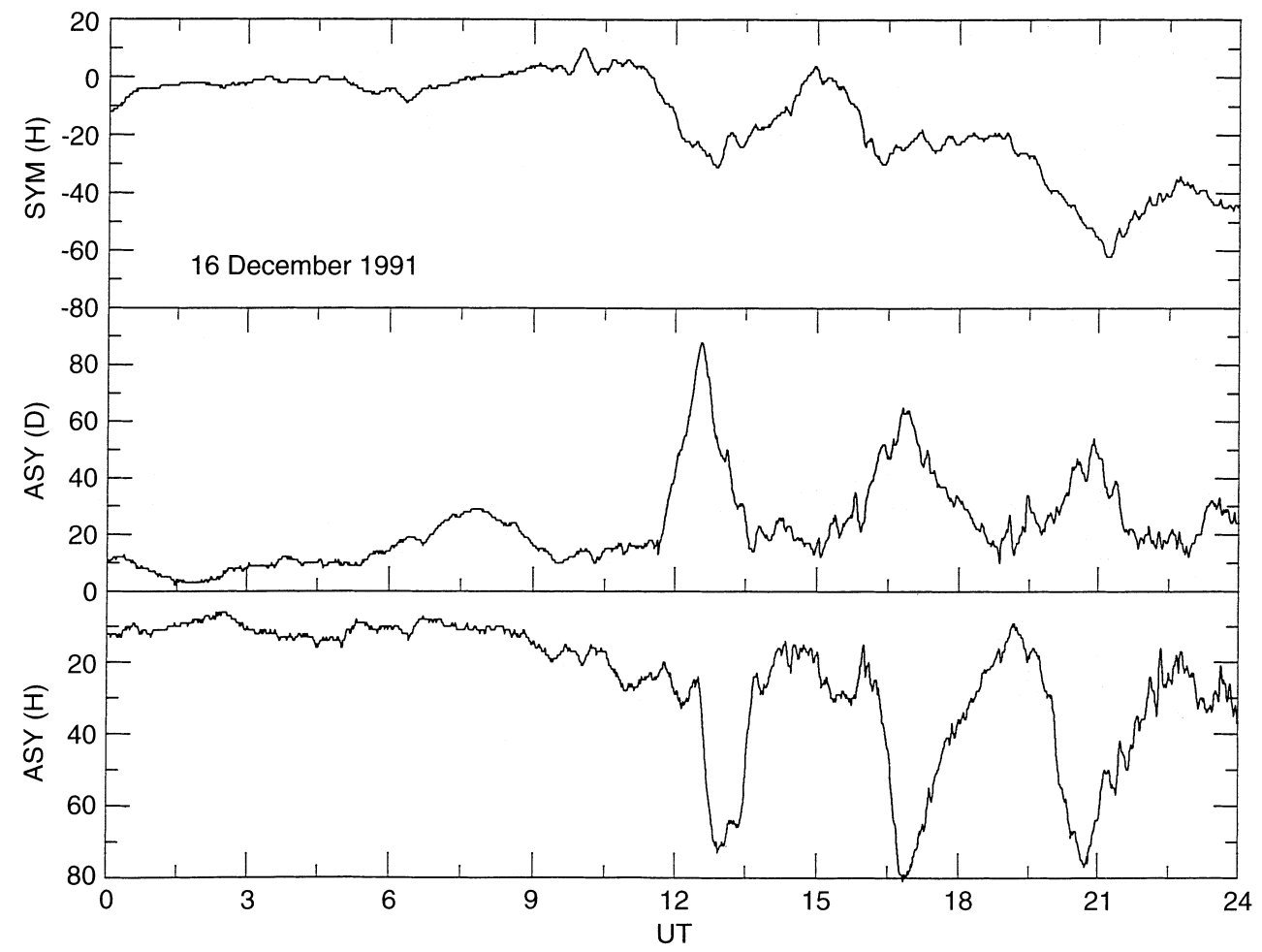

Fig. 1. Time histories of the asymmetric ring current indices, $\operatorname{ASY}(H)$ and $\operatorname{ASY}(D)$ and symmetric ring current index, $\operatorname{SYM}(H)$ on 16 December $1991(\mathrm{Ap}=20)$ based on 1-min resolution data. Note the occurrence of three successive and distinct asymmetric/ symmetric ring current intensifications preceded by quiet conditions 
eastward field followed by westward field in association with the first episode of asymmetric ring current activity. We could not assess the possible presence of a simultaneous electric field disturbance at Fortaleza in the forenoon sector at the time due to the unfortunate gap in ionosonde data.

Beginning around 1500 UT there was a minor development of the asymmetric ring current which tended to decay just before 1600 UT, but which was followed by another large intensification that peaked around 1650 UT. This asymmetric ring current activity had a gradual decay over the next $2.5 \mathrm{~h}$ or so. It is interesting to note from Fig. 2 that the response of vertical plasma drift at Kodaikanal to these ASY variations is evident only till around 1640 UT (2140 LT). The polarity pattern of the response is the same as in the case of the first event around local sunset. In contrast, there is no apparent change in the vertical drift at Kodaikanal during the decay of this event in the local premidnight period (2200-2330 LT). On the other hand, at Fortaleza, which was in the local noon sector at the time, $\mathrm{hpF} 2$ increased during the intensification of asymmetic ring current from $445 \mathrm{~km}$ at 1500 UT (1200 LT) to $596 \mathrm{~km}$ by 1645 UT (1345 LT), i.e. an increase of $151 \mathrm{~km}$ in $105 \mathrm{~min}$, and then decreased by about $50 \mathrm{~km}$ during the recovery phase of the ring current. These changes in $\mathrm{hpF} 2$ which deviate from the quiet-time pattern of a slow and steady increase of $\mathrm{hpF} 2$ of about $3 \mathrm{~m} / \mathrm{s}$ during the daytime period, 0800-1600 LT (see Fig. 2), constitute a signature of a short-lived disturbance in F-layer height at Fortaleza of composite polarity in broad association with the second episode of asymmetric ring current activity.

In comparison, a more impressive and simultaneous response of the zonal electric field in the dusk and predawn hours is seen with the third asymmetric ring current intensification which occurred over the timeinterval 1910-2245 UT. At Kodaikanal, the normal night-time downward vertical drift increased over the period 1910-2049 UT (0010-0149 LT), corresponding to the development phase of the asymmetric ring current, followed by a sharp and prominent reversal to upward direction during the decay phase of the event. The hightime-resolution data showed that the reversal of vertical drift to upward direction is simultaneous with the start of the recovery phase of the asymmetric ring current, as can be seen from Fig. 2. The average value of downward vertical drift over the interval 0010-0149 LT (growth phase of asymmetric ring current) is $13.2 \mathrm{~m} / \mathrm{s}$, while the average value for the preceding interval 2306-0009 LT (prior to the ring current event) is $7.3 \mathrm{~m} / \mathrm{s}$. We consider the enhanced downward drift (by a factor of 1.8) and the subsequent abnormal upward drift that occurred at Kodaikanal in consonance with the development and recovery phases of the asymmetric ring current, respectively, as unambigious evidence for the occurrence of an electric field disturbance of composite polarity there. The very fact that an enhanced downward drift (average $-13.2 \mathrm{~m} / \mathrm{s}$ ) prevailed in the growth phase of the ring current event when the bottomside F-layer at Kodaikanal is in the altitude range $250-260 \mathrm{~km}$ where chemical loss dominates, supports the interpretation. The peak

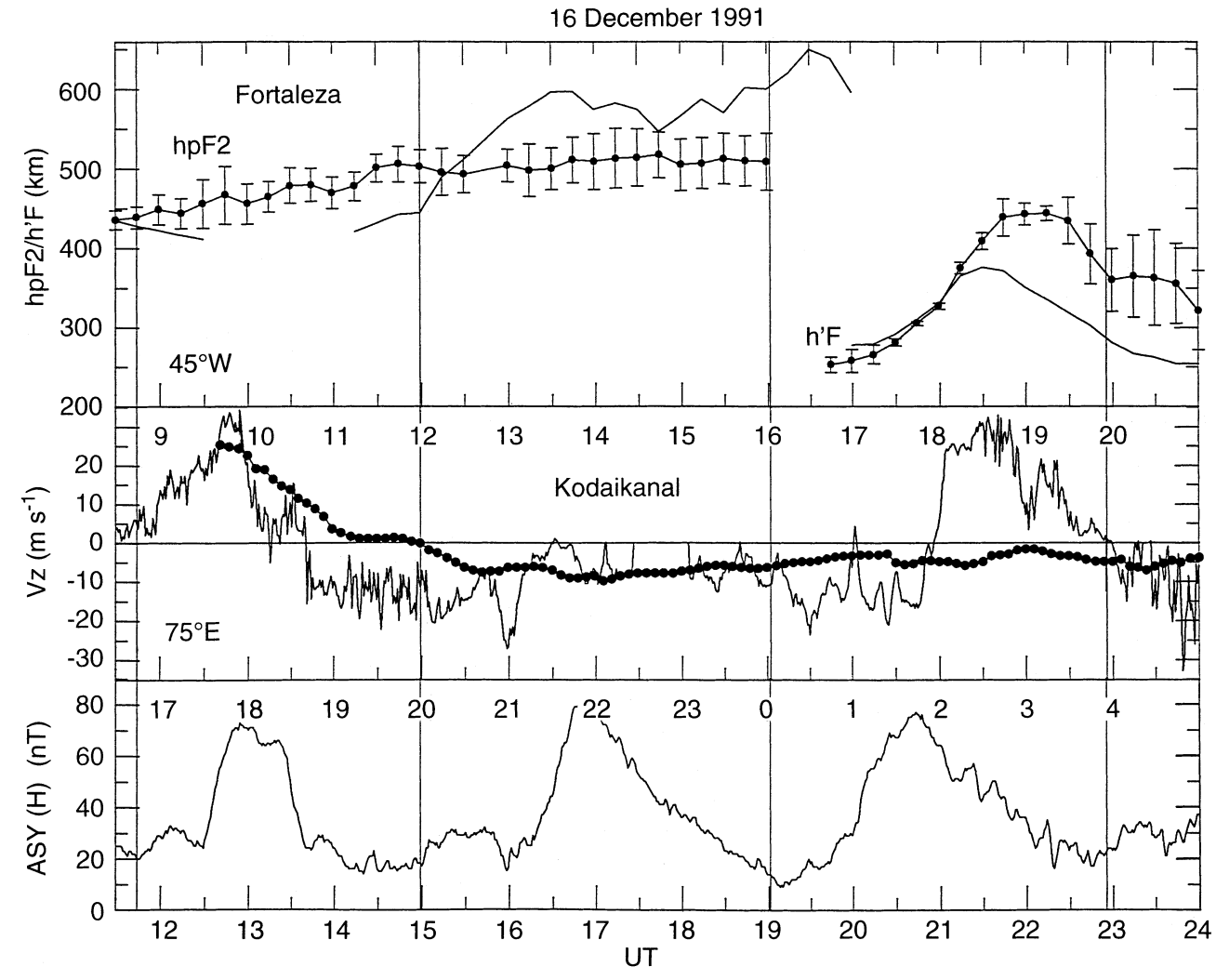

Fig. 2. Time variation of $\operatorname{ASY}(H)$ index, F-region vertical plasma drift, $V_{z}$ over Kodaikanal (dip 4), India and $h p F 2 / h^{\prime} F$ at Fortaleza (dip -9), Brazil on 16 December 1991. The curves with solid circles represent the average quiet-day patterns of the parameters at the two stations. The vertical bars represent standard deviations of the average values of $\mathrm{hpF} 2$ and $\mathrm{h}^{\prime} \mathrm{F}$ at Fortaleza 
value of the anomalous upward drift of about $30 \mathrm{~m} / \mathrm{s}$ in the recovery phase of the ring current represents an eastward electric field of $1.2 \mathrm{mV} / \mathrm{m}$. It is pertinent to mention here that the anomalous downward drift in the postsunset hours and upward drift in the presunrise hours evidenced in the high-time-resolution $V_{z}$ data of Kodaikanal, during the recovery phase of the first and third events of asymmetric ring current activity, are also seen in low-time-resolution (1-h) h'F data from the colocated ionosonde experiment (not shown here).

The third episode of ring current activity also lead to a disturbance in F-region height at Fortaleza in the dusk sector, concurrent with the vertical plasma drift disturbance at Kodaikanal in the predawn hours, but only in its recovery phase. As can be seen from Fig. 2, h'F at Fortaleza showed the normal sunset increase till 1815 LT (2115 UT), but after that it experienced an anomalous decrease from $376 \mathrm{~km}$ at $1830 \mathrm{LT}$ to $254 \mathrm{~km}$ at $2045 \mathrm{LT}$, i.e. a decrease of $122 \mathrm{~km}$ in $135 \mathrm{~min}$ or a gross downward drift of about $10 \mathrm{~m} / \mathrm{s}$ (this is an underestimate because of the counteractive nature of the effect of layer decay due to chemical loss at altitudes below $300 \mathrm{~km}$ ). This behaviour is a significant departure from the quiet-time pattern, wherein the layer experiences the upward drift till about 1930 LT and then steadily decreases, as can be seen from Fig. 2 (see also Batista et al., 1991). The perturbation in F-region height at Fortaleza, which is indicative of a westward electric field disturbance, occurred simultaneously with the eastward disturbance at Kodaikanal, and both correspond to the recovery phase of the asymmetric ring current event. The counterpart of the westward electric field seen at Kodaikanal in the growth phase of the asymmetric ring current is, however, not apparent at Fortaleza situated in the local evening (1610-1749 LT) sector.

To characterise the ionospheric disturbance over Fortaleza, related to the third episode of asymmetric ring current activity on 16 December, we have derived real height profiles of electron density $\left(N_{e^{-}} h\right)$, of the bottomside $\mathrm{F}$ region from the quarter-hourly ionograms using the POLAN algorithm of Titheridge (1985). The $N_{e}-h$ profiles not only confirmed the anomalous and rapid descent of the F-layer in the postsunset period at Fortaleza in consonance with the recovery phase of the third asymmetric ring current event of the day, but also revealed the presence of significant changes in the electron density distribution associated with it. Figure 3 shows the isodensity contours in the height-time domain as derived from the $N_{e}-h$ profiles. It is quite evident from Fig. 3. that, starting at 1845 LT, the entire F-layer rapidly moved downwards accompanied by enhancement in electron density at progressively lower altitudes below the layer peak, i.e., as the vertical drift disturbance pushed the plasma downwards. It may be noted further that although the entire F-layer experienced an apparent downward movement, its magnitude shows an obvious dependence on the electron density level. During the interval 1845-2045 LT, while $\mathrm{h}_{\mathrm{m}}$ decreased by $127 \mathrm{~km}$, the decrease in height of electron density levels of $0.2,0.31,0.44$ and $0.64 \times 10^{6} \mathrm{~cm}^{-3}$ are 131,141 , 156 and $208 \mathrm{~km}$, respectively, as may be seen from
Fig. 3. The reduction in the amplitude of height change with decreasing value of electron density reflects the increasing importance of chemical loss in counteracting the downward movement caused by the westward electric field disturbance, with decrease in altitude.

Measurements of ionospheric electron content (IEC) at São José dos Campos on 16 December 1991 showed a conspicuous increase beginning around 1845 LT compared to the quiet-day pattern, as can be seen from Fig. 4. IEC increased by a factor of 1.26 between 1845 and $2100 \mathrm{LT}$, while the quiet-day trend is a decrease indicative of the postsunset renewal of the fountain process due to the prereversal enhancement of the upward plasma drift. The conspicuous postsunset increase in IEC suggests the equatorward contraction of the crest of the equatorial ionisation anomaly (EIA), because of the downward plasma drift disturbance related to recovery phase of the third episode of asymmetric ring current activity. There also seems to be a weak response in IEC at São Jose dos Campos with an opposite phase to the height disturbance at Fortaleza, associated with the second event of asymmetric ring current activity, as may be seen from Fig. 4 . Coincident with the increase in $\mathrm{hpF} 2$ beginning at 1200 LT (1500 UT), IEC underwent an unmistakable decrease followed by a tendency to increase when $\mathrm{hpF} 2$ showed the trend of a decrease (see Fig. 2).

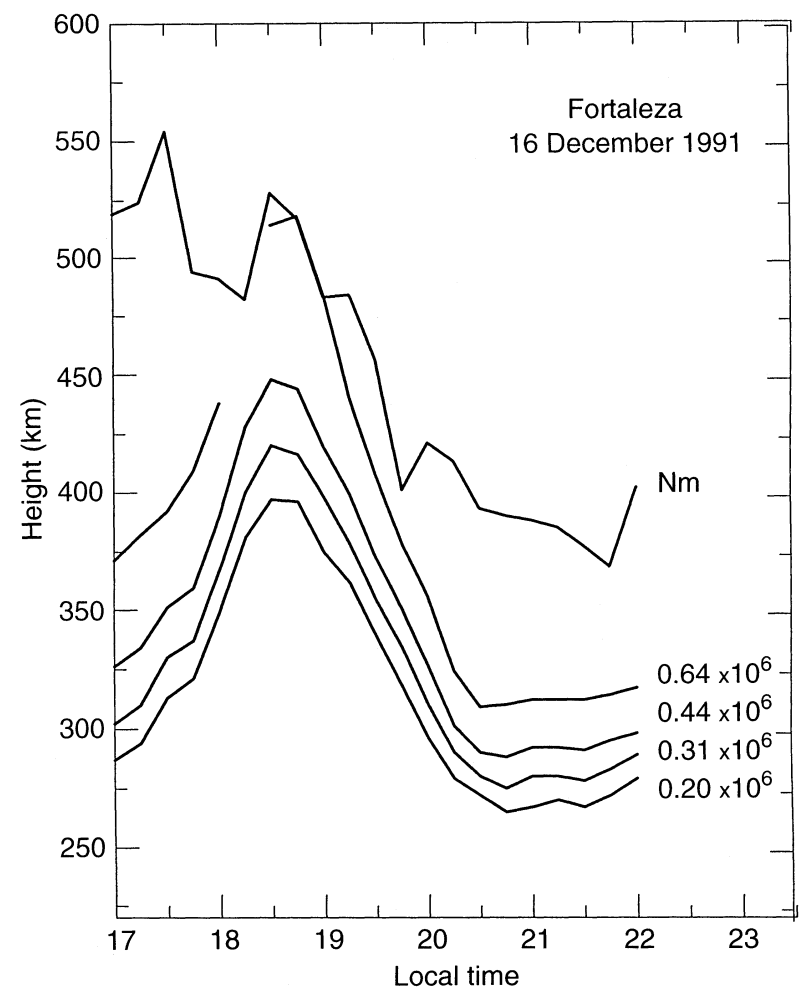

Fig. 3. Height versus time plots of specific electron density levels at Fortaleza for the period 1700-2200 LT on 16 December 1991 as derived from $N_{e}-h$ profile data. Note the rapid drop in the height of isodensity contours over the interval 1845-2045 LT 


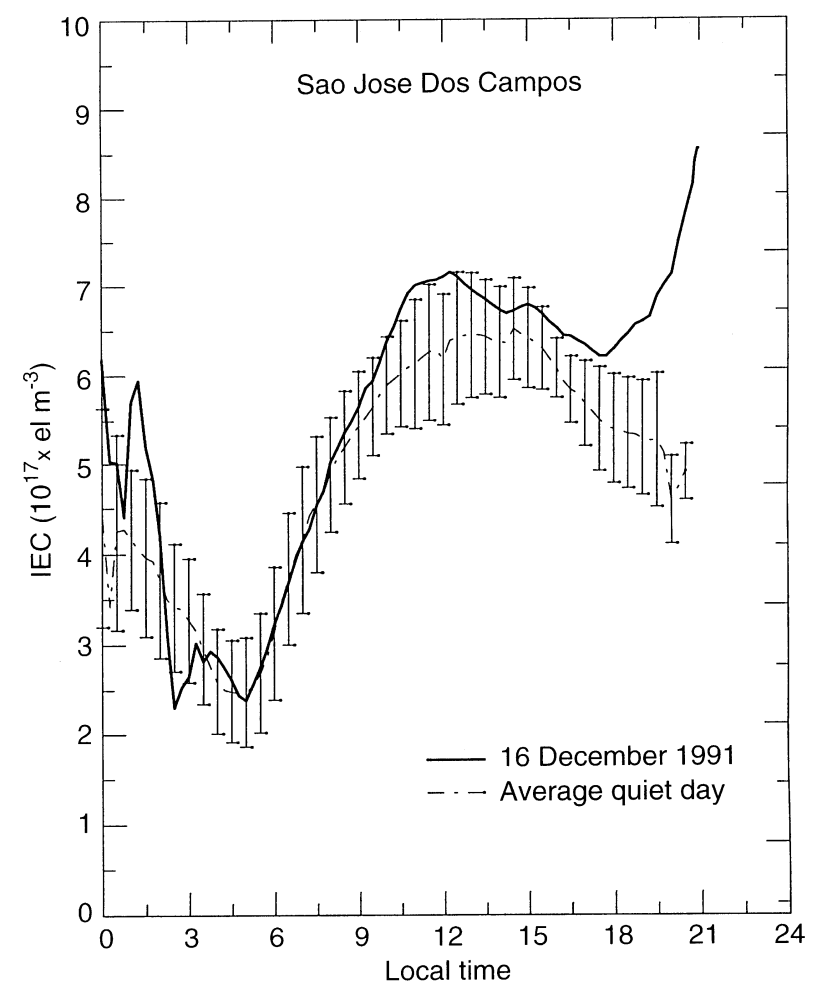

Fig. 4. Diurnal profile of Ionospheric electron content (IEC) at São José dos Campos, Brazil, derived from measurements of Faraday rotation of $136-\mathrm{MHz}$ beacon transmissions of GOES-1 satellite on 16 December 1991. Also shown is the average diurnal pattern of IEC for quiet days of the month (dashed curve) along with standard deviations (vertical bars) of averages

\section{Discussion}

The asymmetric ring current events dealt with here all have the characteristics of mid-latitude positive bays, namely, a rapid increase in $\operatorname{ASY}(H)$ or $\operatorname{ASY}(D)$ $>20 \mathrm{nT}$, a broad maximum and a recovery spanning 1-2 h. The mid-latitude positive bays (with amplitude $>20 \mathrm{nT}$ ) are known to correspond, in general, to rather large substorms (as seen in auroral electrojet indices, AE) and are commonly taken as proxy of substorms (e.g. Abdu et al., 1995; Iyemori and Rao, 1996). It is therefore logical to discuss the results of the present case-studies in terms of physical processes attendant to substorms, in particular, the low-latitude penetration of electric field perturbations of high-latitude origin. The rapidity of the evidenced changes in F-layer vertical drift/height and their close temporal association with asymmetric ring current activity further justify such a discussion.

The geomagnetic substorm or bay disturbance is associated with large enhancements in electric fields and conductivities in the auroral dynamo region originating in a magnetospheric substorm (see Kamide et al., 1996, and references therein). The currently available theoretical models consistently show that a direct or prompt penetration of high-latitude electric fields to the lowlatitude region occurs at such times, with a strong localtime dependence of the amplitude and polarity of the electric field perturbations that characterise the penetration (e.g. Nopper and Carovillano, 1978; Tsunomura and Araki, 1984; Senior and Blanc, 1984; Spiro et al., 1988). For a sudden increase in the polar-cap potential drop (increase in magnetospheric convection), as would occur at the onset of substorms asymmetric ring current activation, the models predict for the dip equatorial region, eastward (westward) electric fields on the dayside (nightside) with the transitions in polarity just prior to midnight (22-00 LT) and in the morning. For a given increase in polar-cap potential drop, the amplitude of the electric field perturbation at the dip equator is maximum in the predawn (02-05 LT) and dusk (18-21 LT) sectors, and minimum just prior to midnight. Electric fields of opposite polarity are to be expected for a sudden decrease in polar-cap potential drop corresponding to the recovery phase of asymmetric ring current events/substorms. Since typically in a substorm the increase in convection at its onset will be followed by a decrease in its recovery phase, transient electric field disturbances of bipolar character representing penetration fields related to both the effects should be seen in succession, during the course of the substorm, at least in principle.

We have shown that the decay of asymmetric ring current (third event on 16 December, see Fig. 2) is associated with simultaneous perturbations in the zonal electric field of opposite polarity in the predawn and postsunset local-time sectors. The polarity of the electric field perturbation is eastward (westward) in the predawn (sunset) sectors and this is consistent with the theoretical/model predictions. That an eastward (westward) electric field disturbance prevails in the presunrise (postsunset) period during the decay phase of isolated asymmetric ring current activity substorms is known from earlier studies based mostly on single-station data (e.g. Gonzales et al., 1979; Sastri et al., 1992b, c; Abdu et al., 1995). But the simultaneous response of the electric field in the dusk and predawn sectors with opposite polarity in such a physical situation is demonstrated for the first time here. This finding, in fact, is a highlight of the present work, and it validates the results of global convection models as regards the high sensitivity of the equatorial zonal electric field in the dusk and predawn sectors to asymmetric ring current/substorm activity. The epoch of intensification of asymmetric ring current is also accompanied by electric field perturbations in the dusk-to-dawn night-time sector with a polarity opposite to that of the recovery phase, namely, westward (eastward) fields in the predawn (dusk) hours. This behaviour is particularly seen in the high-time-resolution $V_{z}$ data of Kodaikanal with the first and third events of asymmetric ring current activity. The only exception to this pattern is the absence of an eastward field (enhanced upward drift) in the postsunset period at Fortaleza with the third event (see Fig. 2.). We shall return to this point later in the paper. Sastri et al. (1992a, b) emphasised the bipolar character of disturbances in equatorial electric field with particular reference to isolated substorm activity. Gonzales et al. (1979, 1983) have also shown earlier that the equatorial zonal 
electric field responds to both rapid decreases and increases in magnetospheric convection. The present work reaffirms the view that at a given location, bipolar electric field disturbances do occur with some, if not all, isolated events of asymmetric ring current activity (substorms).

The circumstances of the asymmetric ring current activity and the database available to us permitted the evaluation of response characteristics in the dayside sector as well, but for only the second event. Here again, small-amplitude perturbations corresponding broadly to the development and decay phases of the asymmetric ring current are seen in hpF2 at Fortaleza with the same polarity pattern as that of the evening sector, namely, eastward field followed by westward field, in that order. In contrast, there is no significant simultaneous response of the electric field in the premidnight sector (in the vertical drift at Kodaikanal) to the decay phase of this event (see Fig. 2). These features are in concordance with the model predictions which show the amplitude of electric field disturbances to be small around midnight and in the afternoon period (see for example Fig. 8 of Fejer et al., 1990b).

The results of the present study are thus in agreement with the predictions of global convection models as regards the bipolar nature of the electric field disturbances, the polarity sequence in individual disturbances with reference to the phase of the asymmetric ring current event and its local-time dependence. We could not attempt a quantitative comparison of the amplitude of the observed electric fields with model predictions due to non-availability of relevant inputs like the interplanetary plasma and magnetic field data for estimating the changes in the polar-cap potetial drop, which is the primary input for the convection models. We would also like to mention in this context that the absence of the (expected) eastward electric field at Fortaleza in the dusk sector during the development phase of the third episode of asymmetric ring current activity is rather disconcerting (such an eastward electric field is, however, seen in the dusktime vertical plasma drift at Kodaikanal with the first event; see also Abdu et al., 1995). Several possible explanations for this behaviour exist. Firstly, this could be due either to a rapid attenuation with latitude of the perturbation electric field (multi-station data along the meridian are needed to verify this, which is beyond the scope of the present paper)-or a faster decay of the same (defying detection in 15-min ionosonde data). It is pertinent to recall here that the model simulations show the eastward electric field perturbation in the dusk sector associated with an increase in magnetospheric convection decays very fast with a time-constant of $\approx 20 \mathrm{~min}$ (Spiro et al., 1988; Fejer et al., 1990a). Secondly, since the third event of asymmetric ring current activity is preceded by geomagnetic activity, one can, in principle, expect a contribution of electric fields of disturbance dynamo mechanism to the patterns of plasma drift/height at Kodaikanal and Fortaleza, respectively. The slowly varying electric fields of disturbance dynamo origin which are eastward (westward) in the postmidnight (dusk) sector will add on to the rapidly varying penetration fields. The net result could at times be a masking of the penetration fields depending on the relative amplitude and polarity of the two disturbance fields. We believe that the absence of an eastward electric field perturbation in the dusk sector (at Fortaleza) during the development of the third episode of asymmetric ring current may be due to such a situation. The fact that the expected westward electric field is, however, seen at Kodaikanal in the postmidnight sector with this phase of the asymmetric ring current event, suggests a strong longitudinal dependence of the disturbance dynamo fields at equatorial latitudes. This viewpoint remains speculative due to the lack of experimental information at the moment of the longitudinal extent of the disturbance dynamo electric fields.

We have shown that a short-lived disturbance in the F-layer electron density distribution occurred at Fortaleza during the time-span of the westward electric field associated with the recovery of the third episode of asymmetric ring current activity on 16 December. Such fast and prominent changes in nocturnal equatorial Flayer plasma density are uncommon, and, to our knowledge, there are only two earlier reports of similar plasma density disturbances, both associated with rapid downward plasma motions (Tan, 1982; Sastri et al., 1992c). The F-region height and plasma density in the dip equatorial region are well known to be quite sensitive during the daytime and evening hours to the vertical plasma drift associated with the zonal electric field, which is the basic ingredient of the fountain process responsible for the equatorial ionization anomaly, EIA (see Abdu et al., 1993, and references therein). Batista et al. (1991) showed that a transient downward drift perturbation (westward electric field) during daytime leads to a lowering of F-region peak height $\left(h_{m}\right)$ and a sharp rise in peak electron density $\left(N_{m}\right)$ near the dip equator. They also showed that a large upward drift disturbance results in a sharp rise in layer height and decrease in $N_{m}$ near the dip equator and poleward expansion of the EIA. The work of Tan (1982) showed that an increase in night-time $N_{m}$ over the dip equator occurs in a limited altitude range above $250 \mathrm{~km}$, if a sufficiently large downward drift prevails such that the ionization convergence induced by the downdraft overcomes the chemical recombination rate. The dusktime increase in electron density at and below the F-layer peak above Fortaleza and in IEC at Sao Jose dos Campos on 16 December thus find a logical explanation in terms of plasma redistribution due to the combined effects of the equatorward retreat of the EIA due to the westward electric field perturbation, and the dominance of plasma convergence due to the abnormal downdraft of the layer over chemical loss in the bottomside $\mathrm{F}$ region.

Acknowledgements. The authors are grateful to Dr Toshi Iyemori, Faculty of Science, Kyoto University, Kyoto, Japan for providing the data of ASY/SYM indices. J. H. Sastri is grateful to Conselho Nacional de Desenvolvimento Cientifico e Tecnologico (CNPq), Brazil, for the award of a Visiting Professor Fellowship. M. A. Abdu and J. H. A. Sobral are also supported by CNPq under the processes CNPq 501956/91-3 and 522919/96/0. The work is 
supported by Fundo Nacional de Desenvolvimento Cientifico e Tecnologico under contract FINEP-537/CT.

Topical Editor D. Alcaydé thanks N. Balan and C. A. Reddy for their help in evaluating this paper.

\section{References}

Abdu, M. A., J. A. Bittencourt, and I. S. Batista, Magnetic declination control of the equatorial F-region dynamo electric field development and spread-F, J. Geophys. Res., 86, 11 44311 446, 1981.

Abdu, M. A., J. H. A. Sobral, E. R. de Paula, and I. S. Batista, Magnetospheric disturbance effects on the equatorial ionization anomaly (EIA): an overview, J. Atmos. Terr. Phys., 53, 757$771,1991$.

Abdu, M. A., G. O. Walker, B. M. Reddy, E. R. de Paula, J. H. A. Sobral, B. G. Fejer, and E. P. Szuszczewicz, Global-scale equatorial ionization anomaly (EIA) response to magnetospheric disturbances based on the May-June 1987 SUNDIAL coordinated observations, Ann. Geophysicae, 11, 585-594, 1993.

Abdu, M. A., Batista, I. S., G. O. Walker, J. H. A. Sobral, N. B. Trivedi, and E. R. de Paula, Equatorial ionospheric electric fields during magnetospheric disturbance: local time/longitude dependences from recent EITS campaigns, J. Atmos. Terr. Phys., 57, 1065-1083, 1995.

Batista, I. S., M. A. Abdu, and J. A. Bittencourt, Equatorial Fregion vertical plasma drifts: seasonal and longitudinal asymmetries in the American sector, J. Geophys. Res., 91, 12 055$12064,1986$.

Batista, I. S., E. R. de Paula, M. A. Abdu, and N. B. Trivedi, Ionospheric effects of the March 13, 1989 magnetic storm at low and equatorial latitudes, J. Geophys. Res., 96, 13 943-13 952, 1991.

Bittencourt, J. A., and M. A. Abdu, A theoretical comparison between apparent and real vertical ionization drift velocities in the equatorial F region, J. Geophys. Res., 86, 2451-2454, 1981.

Blanc, M., and A. D. Richmond, The ionospheric disturbance dynamo, J. Geophys. Res., 85, 1669-1688, 1980.

Clauer, C. R., and R. L. McPherron, The relative importance of the interplanetary electric field and magnetospheric substorm on the partial ring current development, J. Geophys. Res., 85, 67476759, 1980.

Clauer, C. R., R. L. McPherron, and C. Searls, Solar-wind control of the low-latitude asymmetric disturbance field, J. Geophys. Res., 88, 2123-2130, 1983.

Crain, D. J., R. A. Hellis, G. J. Bailey, and A. D. Richmond, Lowlatitude plasma drifts from a simulation of the global atmospheric dynamo, J. Geophys. Res., 98, 6039-6046, 1993.

Earle, G. D., and M. C. Kelley, Spectral studies of the sources of ionospheric electric fields, J. Geophys. Res., 92, 213-224, 1987.

Farley, D. T., E. Bonelli, B. G. Fejer, and M. F. Larsen, The prereversal enhancement of the zonal electric field in the equatorial ionosphere, J. Geophys. Res., 91, 13 723-13 728, 1986.

Fejer, B. G., Low-latitude electrodynamic plasma drifts: a review, J. Atmos. Terr. Phys., 53, 677-693, 1991.

Fejer, B. G., and L. Scherliess, Time-dependent response of equatorial ionospheric electric fields to magnetospheric disturbances, Geophys. Res. Lett., 22, 851-854, 1995.

Fejer, B. G., M. F. Larsen, and D. T. Farley, Equatorial disturbance dynamo electric fields, Geophys. Res. Lett., 10, 5337-5340, 1983.

Fejer, B. G., E. Kudeki and D. T. Farley, Equatorial F-region zonal plasma drifts, J. Geophys. Res., 90, 12 249-12 255, 1985.

Fejer, B. G., R. W. Spiro, R. A. Wolf, and J. G. Foster, Latitudinal variations of perturbation electric fields during magnetically disturbed periods: 1986 SUNDIAL observations and model results, Ann. Geophysicae, 8, 441-454, 1990a.

Fejer, B. G., M. C. Kelley, C. Senior, O. de la Beaujardiere, J. A. Holt, C. A. Tepley, R. Burnside, M. A. Abdu, J. H. A. Sobral, R.
F. Woodman, Y. Kamide, and R. Lepping, Low- and midlatitude ionospheric electric fields during the January 1984 GISMOS campaign, J. Geophys. Res., 95, 2367-2377, 1990b.

Gonzales, C. A., M. C. Kelley, B. G. Fejer, J. F. Vickrey, and R. F. Woodman, Equatorial electric fields during magnetically disturbed periods. 2. Implications of simultaneous auroral and equatorial measurements, J. Geophys. Res., 84, 5803-5812, 1979.

Gonzales, C. A., M. C. Kelley, R. A. Behnke, J. F. Vickery, R. H. Wand, and J. Holt, On the latitudinal variations of the ionospheric electric field during magnetospheric disturbances, J. Geophys. Res., 88, 9135-9143, 1983.

Iyemori, T., and D. R. K. Rao, Decay of the Dst field of geomagnetic disturbance after substorm onset and its implications to storm-substorm relation, Ann. Geophysicae., 14, 608618, 1996.

Kamide, Y., W. Sun, and S.-I. Akasofu, The average ionospheric electrodynamics for the different substorm phases, J. Geophys. Res., 101, 99-109, 1996.

Mazaudier, C., and S. V. Venkateswaran, Delayed ionospheric effects of the geomagnetic storm of March 22, 1979 studied by the sixth co-ordinated data analysis workshop (CDAW-6), Ann. Geophysicae, 8, 511-518, 1990.

Nair, R. B., N. Balan, G. J. Bailey, and P. B. Rao, Spectra of the a.c. electric fields in the post-sunset $F$ region vertical drift at the magnetic equator, Planet. Space Sci., 40, 655-662, 1992.

Nopper, R. W., and R. L. Carovillano, Polar equatorial coupling during magnetically active periods, Geophys. Res. Lett., 5, 699702, 1978 .

Reddy, C. A., and A. Nishida, Magnetospheric substorms and nighttime height changes of the F2 region at middle and low latitudes, J. Geophys. Res., 97, 3039-3061, 1992.

Reddy, C. A., A. Nishida, S. Fukao, and V. V. Somayajulu, Magnetospheric substorm-related electric fields in the ionosphere: discrepancy of an observation with model predictions, Geophys. Res. Lett., 17, 2333-2336, 1990.

Sastri, J. H., Equatorial electric fields of ionospheric disturbance dynamo origin, Ann. Geophysicae., 6, 635-642, 1988.

Sastri, J. H., K. B. Ramesh, and K. S. Ramamurthy, A system for recording phase path variations of ionospheric reflections, Kodaikanal Obs. Bull., 5, 15-25, 1985.

Sastri, J. H., K. B. Ramesh, and D. Karunakaran, On the nature of substorm-related transient electric field disturbances in the equatorial ionosphere, Planet. Space Sci., 40, 95-103, 1992a.

Sastri, J. H., K. B. Ramesh, and H. N. R. Rao, Transient composite electric field disturbances near dip equator associated with auroral substorms, Geophys. Res. Lett., 19, 1451-1454, 1992b.

Sastri, J. H., H. N. R. Rao, and K. B. Ramesh, Response of equatorial ionosphere to the transit of interplanetary magnetic cloud of January 13-15, 1967. Transient disturbance in F region, Planet. Space Sci., 40, 519-534, 1992c.

Senior, C., and M. Blanc, On the control of magnetospheric convection by the spatial distribution of ionospheric conductivities, J. Geophys. Res., 89, 261-284, 1984.

Spiro, R. W., R. A. Wolf, and B. G. Fejer, Penetration of highlatitude electric field effects to low latitudes during SUNDIAL 1984, Ann. Geophysicae., 6, 39-50, 1988.

Tan, A., On the nighttime increase in Nm F2 at Jicamarca on 2-3 February 1965, J. Atmos. Terr. Phys., 44, 377-380, 1982.

Tanaka, T., Severe ionospheric disturbances caused by the sudden responses of the subequatorial ionospheres to geomagnetic storms, J. Geophys. Res., 86, 11 335-11 349, 1981.

Tanaka, T., Low-latitude ionospheric disturbances: results for March 1979 and their global characteristics, Geophys. Res. Lett., 13, 1399-1402, 1986.

Titheridge, J. E., Ionogram analysis with the generalized program, POLAN, Report UAG-93, World Data Center A for STP, Boulder, Col, USA, 1985.

Tsunomura, S., and T. Araki, Numerical analysis of equatorial enhancement of geomagnetic sudden commencement, Planet. Space Sci., 32, 599-604, 1984. 